\title{
The CARET Asbestos-Exposed Cohort: Baseline Characteristics and Comparison to Other Asbestos-Exposed Cohorts
}

\author{
Scott Barnhart, MD, MPH, ${ }^{1 *}$ James Keogh, MD, MPH, ${ }^{3}$ Mark R. Cullen, MD, MPH, ${ }^{4}$ \\ Carl Brodkin, MD, MPH, ${ }^{1}$ Diane Liu, MD, ${ }^{6}$ Gary Goodman, MD, MS, ${ }^{1,2}$ \\ Barbara Valanis, DrPH, ${ }^{5}$ Andrew Glass, MD, ${ }^{5}$ Mark Thornquist, PhD, ${ }^{1,2}$ \\ Linda Rosenstock, MD, MPH, ${ }^{1}$ Gilbert Omenn, MD, PhD, ${ }^{1,2}$ and J ohn Balmes, MD ${ }^{6}$
}

\begin{abstract}
The Carotene and Retinol Efficacy Trial (CARET) was a double-blind, placebo-controlled trial of the daily administration of 25,000 IU vitamin A and $30 \mathrm{mg} \beta$-carotene for the prevention of lung cancer. Of close to 18,500 participants, more than 4,000 were asbestos-exposed men recruited from shipyard and construction trades at five study centers in the United States. While the primary endpoint of the trial was the incidence of lung cancer, a number of questions about the natural history of asbestos-related disease will also be addressed. The mean age at entry into the trial was 57 years and the mean duration of follow-up on active intervention was 4 years. With the exception of 133 never-smoker pilot participants (3\%), all subjects recruited were by intention current (38\%) or ex-smokers (58\%), with a mean cumulative smoking exposure at entry of 43 pack-years. Mean years from first asbestos exposure were 35, and mean duration of asbestos exposure in a high-risk trade was 19 years. The distribution of radiographic abnormalities was as follows: normal, 34\%; parenchymal opacities (ILO profusion score $>1 / 0$ ) alone, 18\%; pleural thickening alone, 27\%; both parenchymal opacities and pleural thickening, 21\%. The CARET cohort, when compared to previously reported asbestos-exposed cohorts, is characterized by substantial asbestos exposure and high proportion of asbestos-related radiographic findings.

The active intervention was halted in 1996, after a mean duration of 40 years. Passive follow-up of the cohort will continue until the year 2000. Am. J. Ind. Med. 32:573-581, 1997. (1) 1997 Wiley-Liss, Inc.
\end{abstract}

KEY WORDS: asbestos; smoking; lung function; vitamin A; $\beta$-carotene

${ }^{1}$ School of Public Health and Community Medicine, University of Washington, Seattle, Washington

2Division of Public Health Sciences, Fred Hutchinson Cancer Research Center, Seattle, Washington

${ }^{3}$ Department of Medicine, University of Maryland, Baltimore, Maryland

${ }^{4}$ Department of Medicine, Yale University, New Haven, Connecticut

${ }^{5}$ Kaiser Permanente Center for Health Research, Portland, Oregon

${ }^{6}$ Department of Medicine, University of California, San Francisco, California

Contract grant sponsor: National Cancer Institute; Contract grant number: U01

CA63673; Contract grant number: U01 CA63674; Contract grant number: U01 CA47989;

Contract grant number: U01 CA48200; Contract grant number: U01 CA48203; Contract grant number: U01 CA48196; Contract grant number: U01 CA52596

*Correspondence to: Scott Barnhart, Harborview Medical Center, Box 359739,

325 9th Avenue, Seattle, WA 98104; E-mail: sbht@u.washington.edu

Accepted for publication 1 April 1997.

\section{INTRODUCTION}

Occupational asbestos exposure in the United States and Canada was common during the 50 years prior to the mid-1970s. Despite extensive study, many questions remain unanswered regarding the natural history of asbestos-related lung disease. These include the relation between asbestos exposure and lung cancer and the predictors of loss of lung function among asbestos-exposed workers [Browne et al., 1986; Cullen, 1987; Mossman and Gee, 1989; Barnhart et al., 1990; Schwartz et al., 1990; Rom et al., 1991].

The Carotene and Retinol Efficacy Trial (CARET) was a double-blind, placebo-controlled chemoprevention trial of the daily administration of 25,000 IU vitamin A (as retinyl 
palmitate) and $30 \mathrm{mg} \beta$-carotene for the prevention of lung cancer [Omenn et al., 1994]. The trial had followed a total of 18,314 participants for a mean of 4.0 years, when active intervention was halted in January 1996 because of a higher rate of lung cancer in the participants receiving the study vitamins than in those receiving placebo [Omenn et al., 1996].

CARET recruited two populations at high risk of lung cancer: 14,254 heavy smokers (men and women) and 4,060 asbestos-exposed men at six study centers in the United States. While the primary endpoint of the trial was an assessment of the potential for vitamin $A$ and $\beta$-carotene to reduce the incidence of lung cancer, it was recognized at the outset that the asbestos-exposed cohort represented a major opportunity to investigate, in a prospective manner, the natural history of asbestos-related lung disease, as well as potential effects of the intervention on progression of asbestos-related lung disease. Specific questions which would be investigated included the relation of respiratory symptoms to pulmonary function, the interactive effects of smoking and asbestos exposure on the genesis of parenchymal fibrosis, the predictors of accelerated loss of ventilatory function, the effect of the study vitamin intervention on loss of ventilatory function, the relation of dietary vitamin intake to baseline ventilatory function, and the relation of parenchymal fibrosis to the risk of respiratory malignancy. This paper describes the baseline characteristics of the CARET cohort with respect to asbestos exposure, smoking status, radiographic findings, spirometric findings, and respiratory symptoms, and compares these baseline findings with those of several previously reported asbestos-exposed cohorts.

\section{MATERIALS AND METHODS}

\section{Overview of the Study}

CARET includes two cohorts at high risk of lung cancer. One cohort consists of men and women who, at randomization, were aged 50-69 years, current smokers, or had quit within 6 years, and have 20 or more pack-years of cigarette smoking history. The second cohort, which is the focus of this paper, is the asbestos-exposed cohort. The asbestos-exposed cohort was recruited by five CARET study centers located in Baltimore, New Haven, Portland (OR), San Francisco, and Seattle. Potential subjects were identified from multiple sources including clinic medical records, union membership rosters, workers' compensation lists, the U.S. Navy, and attorneys. Men were eligible for this asbestos-exposed cohort if they met the following criteria: age 45 to 69 ; current cigarette smoker or had quit smoking within the previous 15 years; occupational asbestos exposure beginning at least 15 years previously. Asbestos exposure was accepted only if the participant had (1) worked in a trade known to be at high risk of asbestos exposure for a minimum of 5 years at least 10 years previously, or (2) a chest radiograph that demonstrated changes consistent with asbestos-related disease and an occupational history consistent with substantial asbestos exposure. CARET defined high-risk trades as asbestos insulators, sheetmetal workers, plumbers/pipefitters, plasterboard workers, boilermakers, shipyard electricians, ship scalers, and ship fitters. A radiograph was considered as having asbestos-related abnormalities sufficient to meet the eligibility criteria if any of the following were present: profusion of small, irregular opacities $\geq 1 / 0$, bilateral pleural thickening of $>2$-mm width, unilateral pleural thickening of $>5-\mathrm{mm}$ width, diaphragmatic plaques, or pleural calcifications. Recruitment of the subjects for the full scale "Efficacy" trial which began in 1989, included and built upon a pilot study which recruited 816 asbestos-exposed subjects from 1985 to 1988 using similar eligibility criteria except there was no smoking criterion and men aged 45-74 years were also eligible [Omenn et al., 1993, 1994]. All subjects gave informed consent to participate in CARET, and the study protocol was approved by the institutional review board at each of the study center sites.

After recording baseline symptoms and obtaining chest radiographs, spirometry, and liver function tests, eligible subjects completed a 3-month "run-in" period during which time they received placebo vitamins. Subjects who took a minimum of $50 \%$ of study vitamins during this placebo run-in, as determined by weights of returned capsule bottles, were randomized to receive either the placebo or intervention vitamins.

\section{Exposure History, Smoking Status, and Symptoms}

At the time of recruitment, all subjects identified their initial year of first occupational asbestos exposure and their primary occupational trade. In addition, subjects completed a modified American Thoracic Society (ATS) Epidemiology Standardization Project questionnaire [Ferris, 1978], as well as a questionnaire on occupational exposures and a food frequency questionnaire.

\section{Chest Radiographs}

A standard posteroanterior chest radiograph was obtained for each participant. All chest radiographs obtained at a study center were read by a local reader trained in the interpretation of radiographs of asbestos-exposed subjects according to a modified International Labour Office (ILO) Classification of Radiographs of Pneumonoconiosis [1980] system [ILO, 1980]. Standard ILO scoring for the classification of small opacities was used, but the system for rating pleural thickening was simplified. The modified pleural 
TABLE I. Baseline Demographic Characteristics by CARET Study Center Male, Asbestos-Exposed Subjects

\begin{tabular}{|c|c|c|c|c|c|c|c|}
\hline & \multirow{2}{*}{$\begin{array}{c}\text { Pilot } \\
\text { Seattle }\end{array}$} & \multicolumn{6}{|c|}{ Efficacy } \\
\hline & & Baltimore & New Haven & Portland & San Fran & Seattle & Total \\
\hline No. Randomized & 816 & 813 & 1,024 & 308 & 854 & 245 & 4,060 \\
\hline \multicolumn{8}{|l|}{ Age } \\
\hline Mean (SD) & $58(8)$ & $58(7)$ & $56(7)$ & $56(7)$ & $57(7)$ & $56(6)$ & $57(7)$ \\
\hline \multicolumn{8}{|l|}{ Race } \\
\hline Caucasian & $762(93 \%)$ & $651(80 \%)$ & $981(96 \%)$ & $295(96 \%)$ & $660(77 \%)$ & $232(95 \%)$ & $3,581(88 \%)$ \\
\hline African-American & $25(3 \%)$ & $155(19 \%)$ & $31(3 \%)$ & $0(0 \%)$ & $90(10 \%)$ & $4(2 \%)$ & $305(7 \%)$ \\
\hline Hispanic & $4(<1 \%)$ & $0(0 \%)$ & $3(<1 \%)$ & $7(2 \%)$ & $64(7 \%)$ & $1(<1 \%)$ & $79(2 \%)$ \\
\hline Asian/Other & $25(3 \%)$ & $7(1 \%)$ & $9(1 \%)$ & $6(2 \%)$ & $40(5 \%)$ & $8(3 \%)$ & $95(2 \%)$ \\
\hline Unknown & $0(0 \%)$ & $0(0 \%)$ & $0(0 \%)$ & $0(0 \%)$ & $0(0 \%)$ & $0(0 \%)$ & $0(0 \%)$ \\
\hline
\end{tabular}

readings included the presence of pleural abnormalities, the extent and width of pleural thickening and whether it was diffuse and/or circumscribed, and the presence or absence of pleural calcifications, and/or diaphragmatic plaques and calcifications, and/or costophrenic angle blunting. In addition, pleural thickening in the standard ILO A category was subcategorized as either $<2 \mathrm{~mm}\left(\mathrm{~A}_{1}\right)$ or $>2 \mathrm{~mm}\left(\mathrm{~A}_{2}\right)$. Costophrenic angle blunting was not assessed for the subset of subjects who enrolled in the pilot study. Chest radiographs during the pilot study were read in a consensus fashion by two of the authors (S.B., L.R.). For the rest of the CARET asbestos-exposed subjects, all films were classified by only one local reader.

To determine inter-reader variability, a nonrandom sample of 48 chest films from the pilot study was selected to assure a mix of films that were normal or had parenchymal and pleural abnormalities. These chest radiographs were then classified by the two consensus readers in Seattle (L.R., S.B.). The classifications of the local readers from Baltimore (J.K.), New Haven (M.C.), and San Francisco (J.B.) were then compared to those of the Seattle consensus readers. (Portland was not included because they had not yet begun recruitment.) Agreement on profusion rating was considered in the following two ways: exact agreement and agreement within one minor category in either direction.

\section{Spirometry}

Spirometry was obtained at the time of the subjects' first visit, as well as at their second (randomization) visit. Spirometry was performed by trained technicians according to ATS standards [ATS, 1987]. Quality assurance procedures included a requirement that they pass a certification test in spirometry and make an effort to obtain a minimum of three acceptable tracings (with a maximum of seven efforts) with reproducibility of forced expiratory volume in $1 \mathrm{sec}\left(\mathrm{FEV}_{1}\right)$ and forced vital capacity (FVC) within 5\% between the two best efforts (ATS, 1987). Baseline spirometry was not performed or data were not complete for $7 \%$ of the participants. Of the spirometric tests performed on the first visit, $87 \%$ met ATS performance criteria; for $7 \%$, variability was greater than $5 \%$; in $2 \%$, the curve was not smooth; in $2 \%$, both variability and curve did not meet ATS criteria; and in 3\%, there were other performance problems. Spirometric tests meeting ATS performance criteria were obtained for an additional $4 \%$ of subjects at the second visit (after a 3-month run-in period of placebo vitamin administration), for a total of $91 \%$. No spirometric tests were excluded, however, on the basis of poor reproducibility alone [ATS, 1987].

Abnormal spirometry results were identified using the prediction equations of Crapo et al. [1981] and the following definitions: normal was defined as FVC $\geq 95 \%$ confidence interval (CI) for the predicted value, $\mathrm{FEV}_{1} / \mathrm{FVC} \geq 95 \% \mathrm{CI}$, and forced expiratory flow of $25-75 \%$ of the forced vital capacity $\left(\mathrm{FEF}_{25-75}\right) \geq 95 \% \mathrm{CI}$; restrictive ventilatory defect was defined as $\mathrm{FVC}<95 \% \mathrm{CI}$ and $\mathrm{FEV}_{1} / \mathrm{FVC} \geq 95 \% \mathrm{CI}$; obstructive ventilatory defect was defined as $\mathrm{FEV}_{1} / \mathrm{FVC}$ $<95 \% \mathrm{CI}$ and $\mathrm{FVC} \geq 95 \% \mathrm{CI}$; mixed obstructive/restrictive defect was defined as $\mathrm{FEV}_{1} / \mathrm{FVC}<95 \% \mathrm{CI}$ and $\mathrm{FVC}$ $<95 \% \mathrm{CI}$; and "small airways" obstructive defect was defined as $\mathrm{FEV}_{1} / \mathrm{FVC}>95 \% \mathrm{CI} \mathrm{FVC} \geq 95 \% \mathrm{CI}$, and $\mathrm{FEF}_{25-75}$ $<95 \%$ CI [Crapo et al., 1981).

\section{RESULTS}

The age and ethnic characteristics of the 4,060 male asbestos-exposed subjects enrolled in CARET are shown by study center in Table I. The mean age at entry into the trial was 57 years with a range in means across study centers from 56-58 years. Of these participants, $88 \%$ identified 
TABLE II. Smoking Status by CARET Study Center: Asbestos-Exposed Cohort

\begin{tabular}{|c|c|c|c|c|c|c|c|}
\hline & \multirow{2}{*}{$\begin{array}{c}\text { Pilot } \\
\text { Seattle }\end{array}$} & \multicolumn{6}{|c|}{ Efficacy } \\
\hline & & Baltimore & New Haven & Portland & San Fran & Seattle & Total \\
\hline \multicolumn{8}{|l|}{ Smoking status } \\
\hline Never & $133(16 \%)$ & - & - & - & - & - & $133(3 \%)$ \\
\hline Former & $506(62 \%)$ & $474(58 \%)$ & $615(60 \%)$ & $147(48 \%)$ & $513(60 \%)$ & $115(47 \%)$ & $2,370(58 \%)$ \\
\hline Current & $177(22 \%)$ & $339(42 \%)$ & $409(40 \%)$ & $161(52 \%)$ & $341(40 \%)$ & $130(53 \%)$ & $1,558(38 \%)$ \\
\hline \multicolumn{8}{|l|}{ Pack-years ${ }^{\mathrm{a}}$} \\
\hline Mean (SD) & $33(22)$ & $43(24)$ & $45(24)$ & $49(23)$ & $43(24)$ & $48(23)$ & $43(24)$ \\
\hline \multicolumn{8}{|l|}{ Cigarettes/day } \\
\hline \multicolumn{8}{|c|}{ Former smokers } \\
\hline Mean (SD) & $23(11)$ & $24(11)$ & $27(12)$ & 27 (11) & $25(12)$ & $30(11)$ & $25(12)$ \\
\hline \multicolumn{8}{|c|}{ Current smokers } \\
\hline Mean (SD) & $23(9)$ & $24(10)$ & $25(10)$ & $27(10)$ & $24(11)$ & $25(9)$ & $24(10)$ \\
\hline \multicolumn{8}{|l|}{ Years quitb } \\
\hline Mean (SD) & $19(11)$ & $7(4)$ & $8(4)$ & $7(4)$ & $7(4)$ & $6(4)$ & $10(8)$ \\
\hline
\end{tabular}

aFormer and current smokers only.

bFormer smokers only.

TABLE III. Asbestos Exposure/Eligibility Criteria: 4,060 CARET Subjects



aCompleted 5 years work in a high-risk trade (by CARET criteria) at least 10 years before first visit.

bILO reading of chest radiograph was used to classify each film as "positive" or "negative" by CARET criteria. Chest radiographic results for 5 participants, ineligible because first asbestos exposure was $<15$ years prior to first visit, are not included.

themselves as Caucasian, $8 \%$ as African-American, $2 \%$ as Hispanic, and $2 \%$ as Asian or from another ethnic group.

\section{Smoking Status}

With the exception of 133 pilot participants, all recruited subjects were current or ex-smokers. The smoking status of the asbestos-exposed subjects is shown by study center in Table II. The proportion of current smokers ranged from a low of $22 \%$ among the pilot cohort, to $53 \%$ among the Efficacy participants recruited at the Seattle study center. The overall proportion of current smokers was 38\%. The mean number of pack-years among ever-smokers ranged from a low of 33 years among the pilot cohort to a high of 49 pack-years at the Portland study center. Mean pack-years for the entire cohort was 43. For former smokers, the mean years since quitting smoking ranged from a high of 19 years for the pilot participants to a low of 6 years for the Seattle participants recruited to the Efficacy study. Mean years since quitting for the entire cohort was 10 years. 
TABLE IV. High-Risk Trade Distribution: CARET Asbestos-Exposed Cohort

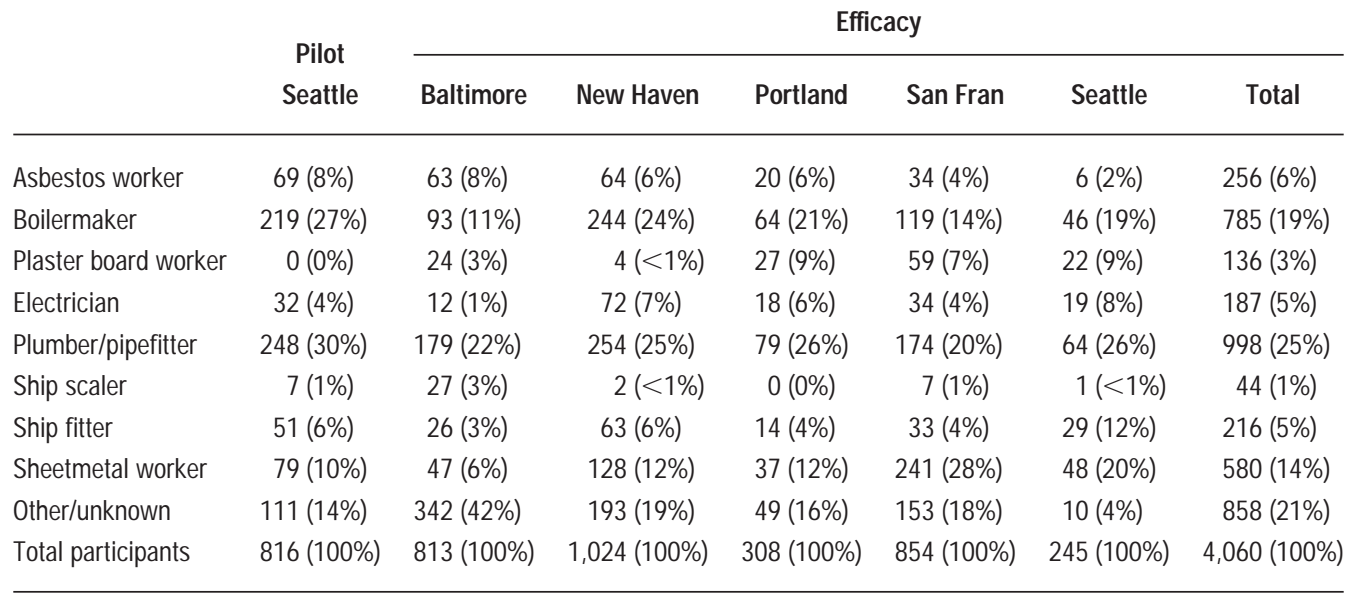

TABLE V. Distribution of Parenchymal and Pleural Abnormalities: CARET Asbestos-Exposed Subjects

\begin{tabular}{lrrrrrrrr} 
& Pilot & \multicolumn{8}{c}{ Efficacy } \\
\cline { 5 - 8 } & Seattle & Baltimore & New Haven & Portland & San Fran & Seattle & Total \\
\hline Chest radiograph results & & & & & & & \\
$\quad$ Negative (\%) & $311(38)$ & $119(15)$ & $352(34)$ & $102(33)$ & $403(47)$ & $108(44)$ & $1,395(34)$ \\
Positive parenchymal onlyb (\%) & $85(10)$ & $237(29)$ & $138(13)$ & $83(27)$ & $167(20)$ & $23(9)$ & $733(18)$ \\
Positive pleural onlyc (\%) & $232(29)$ & $165(20)$ & $369(36)$ & $37(12)$ & $204(24)$ & $72(29)$ & $1,079(27)$ \\
Both positive (\%) & $183(23)$ & $292(36)$ & $165(16)$ & $85(28)$ & $80(9)$ & $41(17)$ & $846(21)$ \\
Unknown/unreported (\%) & $0(0)$ & $0(0)$ & $0(0)$ & $1(<1)$ & $0(0)$ & $1(<1)$ & $2(<1)$ \\
\hline
\end{tabular}

a|LO reading of chest radiograph was used to classify each film as "positive" or "negative" by CARET criteria. Chest radiographic results for 5 participants, ineligible because first asbestos-exposure was $<15$ years prior to first visit, are not included.

blLO profusion of small, irregular opacities $\geq 1 / 0$.

CPositive for pleural changes as defined by CARET (see text).

\section{Asbestos Exposure/ Eligibility Criteria}

To be eligible, participants had to have had occupational asbestos exposure beginning at least 15 years prior to entry; five participants $(0.12 \%)$ were recruited who, upon further review, were found to not meet this criterion. In addition, subjects had to either have worked for a minimum of 5 years in a high-risk trade and had completed those 5 years at least 10 years prior to entry or have a chest radiograph meeting the criteria for asbestos-related abnormalities in the setting of known occupational asbestos exposure. The distribution of participants by asbestos exposure eligibility criteria across the study centers is shown in Table III. The proportion of subjects eligible solely on the basis of a high-risk trade (i.e., having normal radiographs) ranged from a low of $15 \%$ in Baltimore to a high of $47 \%$ in San Francisco, with a mean of $34 \%$. The proportion of participants eligible due to positive chest radiographs alone (i.e., not having worked in a designated high risk trade for an appropriate duration)
TABLE VI. Distribution of ILO Profusion Scores on Enrollment Chest Radiograph: CARET Asbestos-Exposed Cohort

\begin{tabular}{lrrrr} 
ILO score & Frequency & $\%$ & $\begin{array}{c}\text { Cumulative } \\
\text { frequency }\end{array}$ & Cumulative \% \\
\hline $0 /-$ & 8 & 0.2 & 8 & 0.2 \\
$0 / 0$ & 1,243 & 30.6 & 1,251 & 30.8 \\
$0 / 1$ & 1,227 & 30.2 & 2,478 & 61.1 \\
$1 / 0$ & 996 & 24.6 & 3,475 & 85.6 \\
$1 / 1$ & 369 & 9.1 & 3,843 & 94.7 \\
$1 / 2$ & 104 & 2.6 & 3,947 & 97.3 \\
$2 / 1$ & 44 & 1.1 & 3,991 & 98.3 \\
$2 / 2$ & 30 & 0.7 & 4,021 & 99.1 \\
$2 / 3$ & 13 & 0.3 & 4,034 & 99.4 \\
$3 / 2$ & 10 & 0.2 & 4,044 & 99.6 \\
$3 / 3$ & 11 & 0.3 & 4,055 & 99.9 \\
$3 /+$ & 3 & 0.1 & 4,058 & 100 \\
\hline
\end{tabular}


TABLE VII. Pulmonary Function and Respiratory Symptoms: CARET Asbestos-Exposed Cohort

\begin{tabular}{|c|c|c|c|c|c|c|c|}
\hline & \multirow{2}{*}{$\begin{array}{c}\text { Pilot } \\
\text { Seattle }\end{array}$} & \multicolumn{6}{|c|}{ Efficacy } \\
\hline & & Baltimore & New Haven & Portland & San Fran & Seattle & Total \\
\hline \multicolumn{8}{|l|}{ Pulmonary function, ${ }^{a}$ mean (\% predicted) } \\
\hline FVC, L & $4.04(88)$ & $3.76(82)$ & $3.98(86)$ & $4.30(91)$ & $3.96(83)$ & $4.10(87)$ & $3.97(86)$ \\
\hline $\mathrm{FEV}_{1}, \mathrm{~L}$ & $2.95(81)$ & $2.68(74)$ & $2.85(77)$ & $2.98(80)$ & $2.88(77)$ & $2.89(77)$ & $2.86(77)$ \\
\hline $\mathrm{FEF}_{25-75}, \mathrm{~L} / \mathrm{S}$ & $2.32(66)$ & $2.04(57)$ & $2.13(59)$ & $1.96(54)$ & $2.18(60)$ & $2.05(56)$ & $2.14(60)$ \\
\hline $\mathrm{FEV}_{1} / \mathrm{FVC}$ & $0.73(92)$ & $0.71(89)$ & $0.71(90)$ & $0.69(87)$ & $0.73(92)$ & $0.70(88)$ & $0.71(90)$ \\
\hline \multicolumn{8}{|l|}{ Pattern } \\
\hline Normal, \% & 48 & 36 & 40 & 38 & 39 & 36 & 40 \\
\hline Obstructive defect, \% & 31 & 31 & 33 & 44 & 26 & 37 & 32 \\
\hline Restrictive defect, \% & 10 & 16 & 12 & 5 & 18 & 7 & 13 \\
\hline Mixed obstructive/restrictive defect, \% & 9 & 16 & 12 & 9 & 13 & 15 & 12 \\
\hline Small airways obstruction, \% & 1 & 1 & 2 & 4 & 3 & 5 & 2 \\
\hline \multicolumn{8}{|l|}{ Symptoms } \\
\hline Cough, \% & 24 & 31 & 25 & 33 & 26 & 29 & 28 \\
\hline Phlegm, \% & 36 & 40 & 38 & 39 & 40 & 38 & 40 \\
\hline Wheezing, \% & 18 & 28 & 23 & 26 & 23 & 21 & 24 \\
\hline Dyspnea, \% & 53 & 64 & 57 & 51 & 56 & 49 & 57 \\
\hline Grade 1 & 26 & 24 & 35 & 24 & 17 & 36 & 26 \\
\hline Grade 2 & 21 & 22 & 17 & 25 & 24 & 21 & 21 \\
\hline Grade 3 & 33 & 36 & 29 & 34 & 34 & 31 & 33 \\
\hline Grade 4 & 19 & 17 & 19 & 16 & 24 & 12 & 19 \\
\hline
\end{tabular}

aFor the $90 \%$ of participants with adequate spirometry data.

ranged from a low of $4 \%$ in Seattle to a high of $42 \%$ in Baltimore, with a mean of $21 \%$. The high-risk trade distribution by study center is shown in Table IV. Plumbers/ pipe fitters, boilermakers, and sheetmetal workers had the highest representation in the cohort at $25 \%, 19 \%$, and $14 \%$, respectively.

Asbestos exposure was also assessed by the number of years since first asbestos exposure. Mean years from first asbestos exposure was 35 , with little variability across the study centers (Table III). The mean years in a high-risk trade was 19 , ranging from a low of 14 for New Haven to a high of 23 in San Francisco.

\section{Chest Radiographs}

Agreement between the Seattle consensus readers and the single readers in Baltimore, New Haven, and San Francisco for the 48 films from the pilot study center was $50 \%, 44 \%$, and $45 \%$, respectively, for exact agreement; $79 \%, 83 \%$, and $91 \%$ for agreement within one minor category; and $93 \%, 90 \%$, and $88 \%$ for presence of pleural abnormalities.

The distribution of asbestos-related parenchymal and pleural abnormalities on chest radiographs is shown in Table V. The proportion of subjects with a chest radiograph without an asbestos-related abnormality ranged from a low of $15 \%$ at Baltimore, to a high of $47 \%$ at San Francisco, with a mean of $34 \%$. The proportion of chest radiographs showing parenchymal abnormalities alone ranged from a low of $9 \%$ for Seattle Efficacy participants to a high of $29 \%$ at Baltimore, with a mean of $18 \%$. Thirty-nine percent of participants had an ILO profusion score of $1 / 0$ or greater (Table VI). The proportions of participants in the categories of $1 / 0,1 / 1$, and greater than $1 / 1$ were $24.6 \%, 9.1 \%$, and $5.3 \%$, respectively. Pleural abnormalities alone ranged from a low of $12 \%$ at Portland to a high of $36 \%$ at New Haven, $27 \%$ overall. Finally, the percentages of subjects with both pleural and parenchymal abnormalities ranged from a low of 9\% at San Francisco to a high of $36 \%$ at Baltimore, with $21 \%$ overall.

\section{Pulmonary Function Results}

Adequate spirometry data were available for 3,661 (90\%) participants (Table VII). For these participants, the mean FVC was $3.97 \mathrm{~L}$ ( $86 \%$ of predicted); the mean $\mathrm{FEV}_{1}$ was $2.86 \mathrm{~L}$ (77\% of predicted); the mean $\mathrm{FEF}_{25-75}$ was 2.14 $\mathrm{L} / \mathrm{s}$ (60\% of predicted); and the mean $\mathrm{FEV}_{1} / \mathrm{FVC}$ ratio was 0.71 (90\% of predicted) (Fig. 1). The distribution of pulmonary functions findings was as follows: $40 \%$ of 


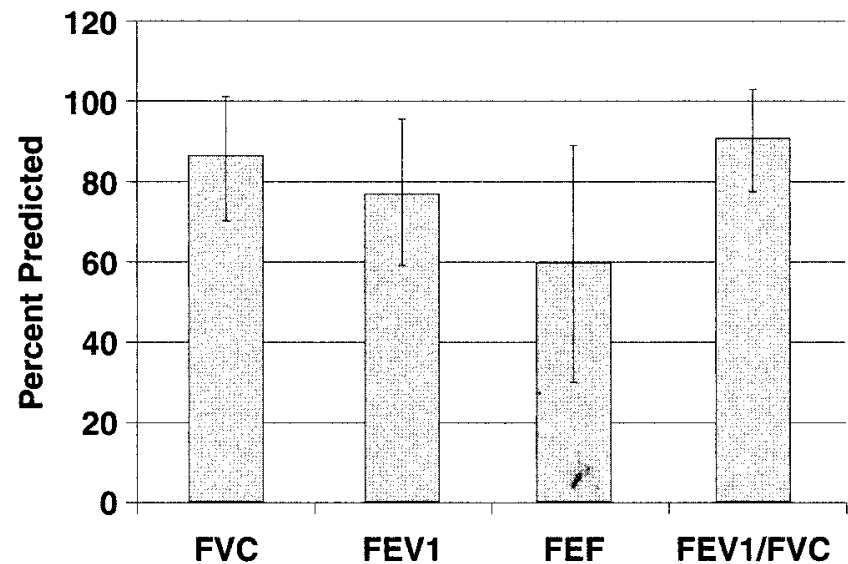

*Error bars are standard deviation

FIGURE 1. Spirometric parameters of pulmonary function for 3,661 asbestosexposed participants of CARET as mean $\pm \mathrm{SE}$ percentage predicted values [Crapo et al., 1981]. FVC, forced vital capacity; $\mathrm{FEV}_{1}=$ forced expiratory volume in $1 \mathrm{sec}$; FEF, forced expiratory flow rate at $25-75 \%$ of the vital capacity.

participants had normal pulmonary function; $32 \%$ had an obstructive ventilatory defect; $13 \%$ had a restrictive ventilatory defect; $12 \%$ had a mixed obstructive/restrictive ventilatory defect; and $2 \%$ had small airways obstruction alone. Percentage predicted $\mathrm{FEV}_{1}$ and $\mathrm{FVC}$ volumes were correlated with ILO profusion scores (Figs. 2, 3).

\section{Respiratory Symptoms}

When symptoms were examined using the ATS questionnaire, the mean proportion of subjects reporting cough, phlegm, or wheezing was $28 \%, 40 \%$, and $24 \%$, respectively. Dyspnea was assessed according to a four-grade scale from the ATS questionnaire. Subjects reporting any dyspnea ranged from a low of $49 \%$ for the Seattle Efficacy participants to a high of $64 \%$ for Baltimore, with an overall mean of $57 \%$. The distribution of grades of dyspnea for those participants who reported it is also presented in Table VII.

\section{DISCUSSION}

The CARET population contains a large cohort of asbestos-exposed participants drawn primarily from the shipyard and construction industries. Eligibility criteria were designed to identify individuals at very high risk of lung cancer. This cohort, when compared to other asbestosexposed cohorts, is characterized by substantial asbestos exposure as measured by time from first exposure and proportion of asbestos-related radiographic findings (Table VIII). Never-smokers were excluded from all but the pilot group.

We developed a model for the incidence of lung cancer as a function of risk factors (age, smoking history, and

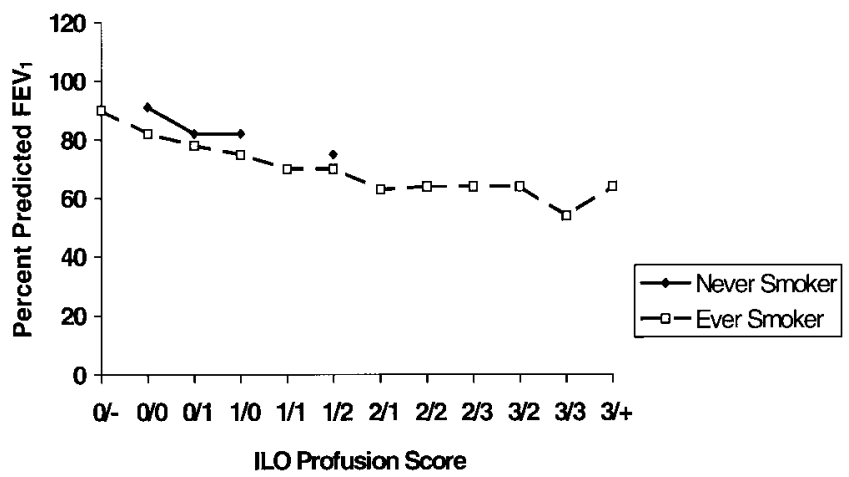

FIGURE 2. Percentage predicted $\mathrm{FEV}_{1}$ plotted against ILO profusion score for 120 never-smoking and 3,541 ever-smoking CARET asbestos-exposed participants. $\mathrm{FEV}_{1}$, forced expiratory volume in I sec; ILO, International Labour Office.

asbestos exposure) in the absence of an intervention [Thornquist et al., 1993]. We used a relative risk of 3 for the effect of asbestos exposure, based on other studies in similar populations [Seidman et al., 1997; Selikoff et al., 1979; Nicholson et al., 1982] and estimated a lung cancer risk of 10 per 1,000 person-years in CARET asbestos-exposed participants. In addition, we estimated a mesothelioma risk of 6 per 1,000 person-years.

The prevalence of asbestos-related findings in the CARET cohort is similar to that of several previously reported cohorts. The proportion of CARET subjects with an ILO profusion score of $1 / 0$ or greater is $39 \%$. Kilburn and co-workers [1985] found the prevalence of a $>1 / 0$ profusion score among shipyard workers to be $41 \%$. Lilis and coworkers [1986] examined radiographic abnormalities among insulation workers and reported the proportion of workers with no abnormalities, parenchymal abnormalities alone, pleural abnormalities alone, or both pleural and parenchymal abnormalities to be $45 \%, 12 \%, 18 \%$, and $26 \%$, respectively. Selikoff and Lilis [1991] reported remarkably similar findings in a study of sheetmetal workers. Our



FIGURE 3. Percentage predicted FVC plotted against IL 0 profusion score for 120 never-smoking and 3,541 ever-smoking CARET asbestos-exposed participants. FVC, forced vital capacity; ILO, International Labour Office. 
TABLE VIII. Comparison of Asbestos Exposure, Smoking, and Chest Radiographic Characteristics of CARET Cohort With Other Asbestos-Exposed Cohorts

\begin{tabular}{|c|c|c|c|c|c|c|c|c|}
\hline \multirow[b]{2}{*}{ Cohort } & \multirow[b]{2}{*}{$\mathbf{N}$} & \multirow{2}{*}{$\begin{array}{c}\text { Asbestos } \\
\text { exposure Latency } \\
\text { (mean years) }\end{array}$} & \multicolumn{2}{|c|}{ Smoking status } & \multicolumn{4}{|c|}{ Chest radiographic findings } \\
\hline & & & $\begin{array}{c}\text { Never-smokers } \\
(\%)\end{array}$ & $\begin{array}{c}\text { Ever-smokers } \\
(\%)\end{array}$ & $\begin{array}{c}\text { Normal } \\
(\%)\end{array}$ & $\begin{array}{c}\text { Parenchymal } \\
\text { alone (\%) }\end{array}$ & $\begin{array}{c}\text { Pleural alone } \\
(\%)\end{array}$ & $\begin{array}{l}\text { Both } \\
(\%)\end{array}$ \\
\hline CARET & 4,060 & 35 & 3 & 97 & 34 & 18 & 27 & 21 \\
\hline Shipyard [Kilburn et al., 1985] & 339 & $\mathrm{~N} / \mathrm{A}$ & 19 & 81 & 36 & 18 & 24 & 23 \\
\hline Shipyard [Selikoff et al., 1980] & 284 & 37 & 20 & 80 & 14 & 32 & 7 & 47 \\
\hline Insulation [Lilis et al., 1986] & 1,117 & 19 & 20 & 80 & 45 & 12 & 18 & 26 \\
\hline Sheetmetal [Selikoff et al., 1991] & 1,016 & 40 & 21 & 79 & 37 & 16 & 28 & 19 \\
\hline Sheetmetal [Welch et al., 1994] & 9,605 & 35 & 24 & 76 & 69 & 7 & 19 & 6 \\
\hline Plumbers/pipefitters [Rosenstock et al., 1988] & 684 & 17 & 28 & 72 & 63 & 7 & 17 & 12 \\
\hline
\end{tabular}

pulmonary function data provide some validation of our chest radiographic data, since reductions in percentage predicted $\mathrm{FEV}_{1}$ and FVC were correlated with ILO profusion scores.

The CARET cohort is a heterogeneous cohort that drew participants from multiple trades and excluded subjects with limited latency or duration of exposure to asbestos. Given the eligibility criteria, the high prevalence of parenchymal fibrosis is not surprising. Because of its selection based on latency and duration, however, the CARET cohort likely overestimates the prevalence of asbestos-related radiographic abnormalities for the various high-risk trades (i.e., by excluding workers with fewer years and shorter latency).

There are several limitations to the use of this cohort to study the natural history of asbestos-related lung disease. First, there exists a potential for respondent bias in terms of misclassifying the extent of asbestos exposure in this cohort of men who volunteered for a prospective randomized chemoprevention trial to reduce the incidence of lung cancer. In addition, the cohort does not represent a broad random cross section of potentially asbestos-exposed workers ranging from those with little asbestos exposure to those with heavy exposure. Rather, the population was selected primarily from trades with high asbestos exposure. Finally, with the exception of some pilot participants, all the participants have a history of current or relatively recent cigarette smoking. The relatively narrow range of both asbestos exposure and smoking behavior may limit the potential to assess in a dose-dependent manner the effect of lower doses of asbestos exposure and smoking on changes in lung function, chest radiographs, or respiratory malignancy.

Despite these limitations, there are few other cohorts for which there exists the opportunity to assess changes in symptoms, lung function, cancer-related morbidity and mortality in a prospective manner. Important questions about the effects of asbestos exposure as well as cigarette smoking still need to be addressed, including the predictors of accelerated loss of lung function and the relationship between parenchymal fibrosis and risk of malignancy. Given the continuing controversy over whether asbestosis is a necessary precursor to lung cancer among asbestos-exposed subjects, the cohort's experience with lung cancer deserves future follow-up (Wilkinson et al., 1995; Hughes et al., 1991]. The CARET cohort represents an important resource for the investigation of the natural history of asbestos-related lung disease.

\section{ACKNOWLEDGMENTS}

The authors thank the staff of the CARET Coordinating Center and the Baltimore, New Haven, Portland, Seattle, and San Francisco study centers for all their hard work to make this clinical trial a success. We are also grateful for the devotion of the CARET participants who volunteered their time and energy to this project.

\section{REFERENCES}

American Thoracic Society (1987): Standardization of spirometry: 1987 update. Am Rev Respir Dis 136:1285-1298.

Barnhart S, Thornquist M, Omenn GS, Goodman G, Feigh P, Rosenstock L (1990): The degree of roentgenographic parenchymal opacities attributable to smoking among asbestos-exposed subjects. Am Rev Respir Dis 141:11021106.

Browne K (1986): Is asbestos or asbestosis the cause of the increased risk of lung cancer in asbestos workers? Br J Ind Med 43:145-149.

Crapo R, Morris A, Gardner R (1981): Reference spirometric values using techniques and equipment that meet the ATS recommendations. Am Rev Respir Dis 123:659-664.

Cullen MR (1987): Controversies in asbestos-related lung cancer. Occup Med 2:259-272. 
Ferris B (1978): Epidemiology Standardization Project. Am Rev Respir Dis 118:1-120.

Hughes JM, Weil H (1991): Asbestosis as a precursor of asbestos-related lung cancer; results of a prospective mortality study. Br J Ind Med 48:229-233.

International Labour Office (1980): "Guidelines for the Use of the ILO International Classification of Radiographs of Pneumoconioses." Geneva: International Labour Office.

Kilburn KH, Warshaw R. Thornton JC (1985): Asbestosis, pulmonary symptoms and functional impairment in shipyard workers. Chest 88:254-259.

Lilis R, Selikoff IJ, Lerman Y, Seidman H, Gelb S (1986): Asbestosis: Interstitial pulmonary fibrosis and pleural fibrosis in a cohort of asbestos insulation workers: influence of cigarette smoking. Am J Ind Med 10:459-470.

Mossman BT, Gee JBL (1989): Asbestos-related diseases. N Engl J Med 320:1721-1730.

Nicholson W, Perkel G, Selikoff IJ. Occupational exposure to asbestos: Population at risk and projected mortality-1980-2030. Am J Ind Med 1982;3:259-311.

Omenn G, Goodman GE, Thornquist MD, Rosenstock L, Barnhart S, Gylys C, Metch B, Lund B (1993): The Carotene and Retinol Efficacy Trial (CARET) to prevent lung cancer in high-risk populations: Pilot study with asbestos-exposed workers. Cancer Epidemiol Biomarkers Prev 2:381-387.

Omenn GS, Goodman GE, Thornquist M, Grizzle J, Rosenstock L, Barnhart S, Balmes J, Cherniack M, Cullen M, Glass A, Keogh J, Meyskens F Jr, Valanis B, Williams J Jr (1994): The Beta-Carotene and Retinol Efficacy Trial (CARET) for chemoprevention of lung cancer in high-risk populations: smokers and asbestos-exposed workers. Cancer Res 54:2038S-2043S.

Omenn GS, Goodman GE, Thornquist MD, Balmes J, Cullen MR, Glass A, Keogh JP, Meyskens FL, Valanis B, Williams JH, Barnhart S, Hammar S (1996): Effects of a combination of beta carotene and vitamin A on lung cancer and cardiovascular disease. N Engl J Med 334:1150-1155.
Rom WN, Travis WO, Brody AR (1991): Cellular and molecular basis of the asbestos-related diseases. Am Rev Respir Dis 143:408-422.

Rosenstock L, Barnhart S, Heyer NJ, Pierson DJ, Hudson LD (1988): Relation among pulmonary function, chest roentgenographic abnormalities, and smoking status in an asbestos-exposed cohort. Am Rev Respir Dis 138:272-277.

Schwartz DA, Fuortes LJ, Galvin JR, Burmeister LF, Schmidt LE, Leistikow BN, LaMarte FP, Merchant JM (1990): Asbestos-induced pleural fibrosis and impaired lung function. Am Rev Respir Dis 141:321-326.

Seidman H, Selikoff IJ, Hammond EC. Short-term asbestos work exposure and long-term observation. Ann NY Acad Sci. 1979;330:61-89.

Selikoff IJ, Hammond EC, Seidman H. Mortality experience of insulation workers in the United States and Canada. Ann NY Acad Sci. 1979;330:91116.

Selikoff IJ, Lilis R (1991): Radiological abnormalities among sheet metal workers in the construction industry in the United States and Canada: Relationship to exposure. Arch Environ Health 46:30-36.

Selikoff IJ, Nicholson WJ, Lilis R (1980): Radiological evidence of asbestos disease among ship repair workers. Am J Ind Med 1:9-22.

Thornquist M, Omenn G, Goodman G, Grizzle J, Rosenstock L, Barnhart S, Anderson G, Hammar S, Balmes J, Cherniak M, Cone J, Glass A, Keogh J, Meyskens F, Valanis B, Williams J. Statistical design and monitoring of the carotene and retinol efficacy trial (CARET). Control Clin Trials. 1993;14:4: $308-24$.

Welch LS, Michaels D, Zoloth SR, and the National Sheet Metal Examination Group (1994): The National Sheet Metal Workers Asbestos Disease Screening Program: radiologic findings. Am J Ind Med 25:635648.

Wilkinson P, Hansell DM, Janssens J, Rubens M, Rudd RM, Taylor AN, McDonald C, (1995): Is lung cancer associated with asbestos exposure when there are no small opacities on the chest radeograph. Lancet 345:1074-1078. 